\title{
Occasional Review-HLA and Leprosy: a Re-evaluation
}

\author{
W VAN EDEN \& R R P DE VRIES \\ Department of Immunohaematology and Bloodbank, University \\ Hospital Leiden, Rijnsburgerweg 10, 2333 AA Leiden, The Nether- \\ lands
}

\section{Introduction}

The discovery in experimental animals of immune response genes (Ir-genes) located in the Major Histocompatibility Complex (MHC), provided an impetus for exploring HLA - the human MHC - encoded genetic control of the immune response in man. In this area particular attention was paid to leprosy on the supposition that genetic factors were involved in this disease, in the variable immune status of the patients, and in the specific immune defect in leprosyaffected patients. In many studies on the distribution of HLA-phenotypes among groups of patients and controls and among the members of multi-case leprosy families a role for HLA-encoded factors in the susceptibility to leprosy was shown, but entirely and quite unexpectedly, to tuberculoid leprosy and not lepromatous leprosy. These studies were reviewed previously. ${ }^{1}$ However, more recent studies gave convincing support to a more general role for HLA in determining the type of the disease to develop following infection. At the present stage it seems justified to state that the susceptibility to both polar tuberculoid (TT) and lepromatous (BL/LL) leprosy is controlled, at least partly, by HLA-linked genes and that these genes do not influence susceptibility to leprosy per se, but rather determine the type of disease to develop, most probably by controlling the leprosy-specific immune response.

Recent findings based on population - and family studies as well as in vitro experiments, to investigate the role of HLA in leprosy - will be discussed in the present review.

\section{The biological significance of the HLA-system}

The HLA-system is recognized as a major immunogenetic and histocompatibility system, coding for a large multi-allelic family of cell-membrane molecules and glycoproteins, present on the cell membrane of virtually all nucleated cells. Since 
the HLA-molecules were originally detected on leucocytes, the initials 'HL' (Human Leucocyte) were given. However, these initials may equally well be considered to indicate Histocompatibility Locus. 'A' is commonly supposed to stand for Antigen, although originally it indicated that it was the first system of its kind to be recognized in man. For a description of the genetic aspects of the HLA-system see previous review papers. ${ }^{1-3} \mathrm{~A}$ unique feature of the HLA-system, undoubtedly closely related to its biological significance, is its extraordinary polymorphism. How such polymorphism could have been maintained during evolution began to be appreciated from the findings that the products of the HLA-system were central in determining the immune response. At present it is well known that T-lymphocytes, in their function as regulator and as effector cells in the immune response, recognize foreign antigens in association with products of the HLA-system. This phenomenon, called HLA-restriction has been described extensively. ${ }^{4} \mathrm{With}$ respect to this phenomenon it has been shown that a foreign antigen may be recognized in association with certain HLA-antigens more efficiently than in association with others. Therefore, the range of antigens present on the variety of offending pathogens recognized by the immune system of an individual host, may be determined, at least partly, by the complexity of the host HLA-system. The ensuing advantage of the heterozygous individual may be one of the driving forces in maintaining the polymorphism of the system. ${ }^{5}$

As a corollary of the biological significance of the system, the presence of individuals with varying immunological potential to a given antigenic challenge was to be anticipated. It is not surprising, therefore, that the HLA-system was found to influence the degree of susceptibility or resistance to diseases implicating the immune system.

\section{HLA and infectious disease}

Although the HLA-system is assumed to be critical to the way the body deals with infectious agents, the number of studies on HLA and infectious diseases has remained small as compared to the number of studies addressing themselves to non-infectious diseases. A plausible explanation for this could be that infectious diseases have nowadays become a public health problem of primary importance in the tropics and third world countries, whereas the HLA-laboratories have been concentrated, so far, in the developed countries. Nevertheless, in the field of HLA and infectious disease, some progress has been made and evidence for a role of HLA-determinants in infectious diseases is accumulating. ${ }^{6}$

A considerable number of studies, however, failed in tracing down HLAencoded factors as risk factors for inf ection. ${ }^{7}$ This could be interpreted to indicate that most deleterious susceptibility factors have been lost during evolution and that only factors imposing subtle differences in resistance have remained in existence, especially with respect to diseases with high-case fatality rates early in life. Another factor contributing to the failure of studies designed to detect 
HLA-encoded control of infectious disease could be 'disease heterogeneity'. Bearing in mind the potential role of the HLA-system in guiding the immune response both in a quantitative and in a qualitative way, the influence of HLA could become reflected in the height or the type of immune response generated during infection. For this reason the patient groups under study should be carefully screened for heterogeneity of immunological aspects during infection or for heterogeneity of eventual immuno-(patho-)logical consequences of the disease. Additional confounding effects may result from environmental factors. Differences in individual level of exposure to an infectious agent obviously constitutes one of the environmental factors which contributes to the differential occurrence of the disease among the population and may well obscure a possible modest effect of HLA on disease resistance. Finally, successful detection of HLA-encoded risk factors could have been hampered by the incomplete recognition of the relevant products of the HLA-system, being especially pertinent to the HLA-D/DR region, the region within the HLA-system harbouring the majority of genes relevant to the regulation of the immune response.

\section{Leprosy: 'a model disease'}

The etiological agent in leprosy, Mycobacterium leprae, is in itself virtually non-toxic. Clinical symptoms of the disease, such as nerve damage, depend largely upon immune reactions directed against the microorganism or antigenic substances liberated from it. Acknowledging the unique opportunities in leprosy to study the immune mechanisms resulting from host-parasite interactions, it was stated by Harboe \& Closs that leprosy is developing as a 'model disease, which provides essential information on the importance of immune reactions in several chronic infectious diseases' ${ }^{8}$

One of the most intriguing features of leprosy is the obvious inter-individual variety in symptomatology to develop after infection. The majority of individuals are fully resistant or develop an effective immune response upon exposure to $M$. leprae, protecting them from developing disease. A minority, on the contrary, are lacking resistance or effective immune reactivity and will develop the disease after becoming infected. Apparently, depending on the degree of immune response that is subsequently generated, either 'low resistant' or 'high resistant' forms of the disease will develop. Following the leprosy spectrum, ${ }^{9}$ starting with polar tuberculoid leprosy (TT) and ending up with polar lepromatous leprosy (LL), a continuous decrease of activity of cell-mediated immunity is found. ${ }^{10}$ By now it has become widely accepted that host-dependent variation in immune status is responsible for the diversity of the clinical appearance of leprosy, although the host factors determining the host-immune status towards $M$. leprae still remain to be elucidated. However, mainly as a result of recently obtained information on HLA and leprosy, a possible role of genetic factors in this regard has presently 
received renewed interest. Crucial in studying how host factors determine the host-immune status could be the proper delineation of the nature of the immune defect in leprosy. In this respect much attention has been paid to the anergic state of lepromatous leprosy. Besides some degree of a generalized depression of the cell-mediated immunity in this type of leprosy, the deficiency of cell-mediated immunity specific for $M$. leprae is more pronounced and seems to be irreversible following successful treatment of the disease. ${ }^{11,12}$ The pre-existence of the defect prior to the development of clinical disease or the presence of the def ect in healthy individuals is controversial. ${ }^{13}$

The nature of the immune defect underlying the specific anergy in lepromatous leprosy has been investigated by various approaches. Evidence was collected in favour of roughly three different mechanisms, which show remarkable similarities with the mechanisms proposed to be responsible for MHC-linked Ir gene defects. Firstly, lepromatous leprosy patients have been shown to lack circulating T-lymphocytes capable of responding to $M$. leprae in the lymphocyte transformation test. ${ }^{14,15}$ Secondly, abnormal macrophage function with defective presentation of $M$. leprae antigens to the immune system in lepromatous leprosy has been reported. ${ }^{16}$ Thirdly, evidence for suppression of the immune response by suppressor T-cells in lepromatous leprosy was obtained. ${ }^{17}$ The recent observation that the leprosy specific non-responsiveness in vitro appeared to be reversible upon the addition of interleukin 2, provides additional support for the third mechanism. ${ }^{18}$ Nevertheless, although the third mechanism seems the most plausible and attractive, in essence the question of the nature of the immune defect in lepromatous leprosy is still open. The immunological defect leading to the development of (polar) tuberculoid leprosy has remained even more obscure. Although in some experiments the presence of suppressor T-cells was shown to be a feature of tuberculoid leprosy and not of lepromatous leprosy, ${ }^{19}$ so far no specific immune defect has been found in relation to tuberculoid leprosy.

\section{Genetics of leprosy}

The first studies concerning heredity and leprosy date back to the $1840 \mathrm{~s}$, when Danielssen \& Boeck ${ }^{20}$ concluded that there was a definite familial spread of leprosy. However, since the discovery of $M$. leprae as the causative organism in 1874 by Hansen, the hereditary aspects of leprosy were long neglected. Although Aycock \& McKinley ${ }^{21}$ speculated on a role of genetic factors in the resistance to leprosy among family-members, a proper reassessment of genetics and leprosy started with Spicket ${ }^{22}$ who attributed both the relative restriction of leprosy to certain ethnic groups and the differential occurrence of leprosy among families to genetic factors. Furthermore, he considered the type of leprosy to be influenced by genetic factors in a multifactorial way. Additional data favouring genetic aspects of the type of leprosy within families were collected by Beiguelman. ${ }^{23} \mathrm{He}$ 
observed a relatively high concordance of leprosy type among sib-pairs and stated that children of lepromatous parents tended to develop lepromatous leprosy. He also studied lepromin skin-test responses within families and among twins. Despite the rather nebulous outcome of these studies, they were interpreted to show genetic aspects of the predisposition to leprosy. A more thorough twin-study was carried out by Chakravartti \& Vogel. ${ }^{24}$ Although the outcome of this study may to some extent have been confounded by ascertainment bias, a number of interesting observations were made. Among 62 monozygotic twinpairs 37 were found to be concordant for leprosy, as compared to eight being concordant for leprosy among 40 dizygotic twin-pairs. Among pairs of which at least one twin had lepromatous leprosy, the concordance for lepromatous leprosy was $70 \%$ for monozygotic pairs and only $20 \%$ for dizygotic pairs. From these twin data it was concluded that the risk of developing leprosy depends both on genetic and on environmental factors and that the type of leprosy is strongly influenced by genetic factors. More recently, on the basis of a complex segregation analysis in families, $\mathrm{Smith}^{25}$ showed genetic control of susceptibility to lepromatous leprosy. An argument was put forth in favour of a multifactorial model of genetic control with a heretability of about $80 \%$. Additional and similar pedigree data on leprosy, collected by Serjeantson et al., ${ }^{26}$ were also demonstrated to fit a multifactorial model.

In conclusion, the number of studies indicating genetic control in leprosy has been substantial, but the data generated have remained frequently multi-interpretable and subject to dispute. ${ }^{27}$

\section{Studies of HLA and tuberculoid leprosy}

Since the time the HLA-system was supposed to contain genes playing a role in regulating the immune response, various studies were carried out analysing HLA-A and -B antigen distributions among leprosy patients and healthy controls in different populations. ${ }^{28-43}$ Due to differences in or absence of a proper classification of the patients and doubtf ul appropriateness of the selected control groups in some instances, it is difficult to make proper comparisons. Nevertheless, the frequencies of two HLA-specificities have been observed repeatedly to differ between patients and controls. HLA-A9 was observed to be decreased among tuberculoid leprosy patients in Thailand, ${ }^{37,39,41}$ among Chinese tuberculoid leprosy patients from Singapore ${ }^{42}$ and among non-lepromatous leprosy-affected patients in India. ${ }^{33}$ An increase of HLA-A9 has been reported for lepromatous leprosy patients in Japan. ${ }^{38}$ It has been found that HLA-B17 has increased among tuberculoid leprosy patients in Thailand ${ }^{37,39,41}$ and in Singapore (Chinese). ${ }^{42}$ Additional associations, remaining significant after correction for the number of comparisons made and not being disputed by subsequent studies, have been reported for HLA-Bw21 with tuberculoid leprosy in Ethiopia ${ }^{28}$ and for HLA-B14 with lepromatous leprosy in Spain. ${ }^{30}$ 
Reviewing all data concerning HLA-A and -B associations with leprosy, the conclusion seems inevitable that the evidence in favour of a role for HLA-A and -B determinants in leprosy is not impressive. A number of studies provided no evidence at all, whereas the associations reported are mostly weak and confined to the population studied. The explanation for this situation may be that the HLA-A and -B antigens are not directly responsible for the differential leprosy susceptibility, but that they do occur in some populations in linkage disequilibrium ${ }^{44}$ with the hypothetical 'susceptibility genes' for leprosy.

The method of first choice to overcome difficulties imposed by populationdependent differences in linkage disequilibrium is the study of families. Moreover, family studies may even reveal HLA-linked control in the absence of associations at the population level. In three family studies, one carried out in Surinam ${ }^{45}$ and two carried out in India, ${ }^{46,47}$ a segregation analysis has provided evidence in favour of recessive HLA-linked factors conferring susceptibility to polar tuberculoid leprosy. Data collected were insufficient to allow a proper assessment of HLA-linked control of other forms of leprosy. The result of a recently reported classical linkage analysis of the above-mentioned family data and some additional family data by the method of lod-scoring has not provided essential additional information regarding the previously reported ${ }^{46,47}$ recessive inheritance of HLA-linked susceptibility to tuberculoid leprosy. ${ }^{48}$ In one of the above-mentioned family studies in India ${ }^{46}$ HLA-DR2 was observed to be associated with tuberculoid leprosy. Although this finding was confirmed in a subsequent family study, ${ }^{49}$ the frequency of DR2 among sporadic cases of tuberculoid leprosy in the same Indian area was shown not to be increased, ${ }^{50}$ suggesting a genetic heterogeneity between familial and sporadic tuberculoid leprosy. However, independent studies in other populations did show an association of HLA-DR2 with tuberculoid leprosy. ${ }^{51-53}$ Also, in Japanese studies, DR2 was shown to be associated with lepromatous leprosy ${ }^{52,53}$ and in a different Japanese study, restricted to tuberculoid leprosy, the increase of DR2 among the patients was found to be secondary to an association with HLA-MT1, one of the more recently detected HLA-class II determinants. ${ }^{54}$ In the other above-mentioned studies ${ }^{52,53}$ HLA-MT1 was also found to be increased among tuberculoid leprosy patients and to an even greater extent among patients with lepromatous leprosy. On the basis of the above data on HLA and leprosy, HLA-linked control of susceptibility to tuberculoid leprosy seems likely. Furthermore, the prediction based on functional grounds that more consistent associations would be detected with HLA-DR or additional class-II products, seems to be true.

\section{Recent studies implicating a role of HLA in the susceptibility to lepromatous leprosy}

One of the studies suggesting a role of HLA, not only in the susceptibility to tuberculoid leprosy, but also to lepromatous leprosy has already been 
mentioned. ${ }^{1}$ Among a group of mixed Caucasoid-Negroid patients originating from Surinam not only was a higher frequency of DR3 observed among TT leprosy patients as compared to healthy controls, but also DR3 was found to be almost absent among lepromatous (BL and LL) patients. ${ }^{55}$ This indicated that in this population HLA-DR3 or an HLA-DR3 associated factor confers resistance to lepromatous leprosy. The markedly decreased frequency of DR3 among lepromatous patients from this population, which was not observed for DR2 among the lepromatous patients from studies showing an association between TT leprosy and DR2, indicates that the DR3-associated control of leprosy type is different from the previously discussed one associated with DR2. Therefore, the observation that susceptibility to polar tuberculoid leprosy is associated with DR2 in India and with DR3 in Surinam, is most likely explained by the existence of different genes, which may predispose to tuberculoid leprosy. Alternatively this discrepancy may be explained by the action of other genes not linked to HLA present in the population. In both situations the relevant HLA-linked gene(s) may be either DR itself, or a separate gene(s) in linkage disequilibrium with DR2 or DR3, depending on the population examined. In two of the previously described population studies data on HLA-DR 3 both show an increased (but not significant) frequency of DR 3 among tuberculoid leprosy patients. ${ }^{50,51}$ In the Japanese population HLA-DR3 does not occur. $^{52,54}$

More convincing data, suggesting a role of HLA in lepromatous leprosy, were obtained from recent HLA-haplotype segregation data of multi-case lepromatous leprosy families from Venezuela. ${ }^{56}$ Although hardly any information based on families with lepromatous leprosy was obtained previously, there seemed to be a general agreement that any non-random inheritance of HLA-haplotypes in leprosy families would be confined to tuberculoid offspring. ${ }^{1,57,48}$ The family data from Venezuela, however, attempted to break with this ill-based dogma. The segregation pattern was found to be highly non-random, especially for haplotypes derived from lepromatous (BL and LL) leprosy-affected parents. In the same families from Venezuela the non-random segregation of HLA-haplotypes in polar tuberculoid leprosy patients was confirmed, indicating again recessive HLA-linked susceptibility to tuberculoid leprosy. Some of these segregation data are shown in Table 1. The data for lepromatous (LL/BL) leprosy-affected siblings indicate convincingly the presence of HLA-linked genes predisposing to lepromatous leprosy. In particular, the finding that the HLA-haplotype segregation for parents affected with lepromatous leprosy was observed to occur non-randomly, suggests a dominant pattern of inheritance of the predisposition to lepromatous leprosy. A similar non-random distribution of parental HLAhaplotypes among lepromatous leprosy affected sibs was observed in a recent family study carried out in China ${ }^{58}$ However, since in the latter study hardly any families were available with parents suffering from lepromatous leprosy no support for the dominant character of this HLA-linked control of lepromatous 
Table 1. Parental HLA-haplotype segregation in multi-case leprosy families from Venezuela

\begin{tabular}{|c|c|c|c|c|c|c|}
\hline Siblings & Parents & $\begin{array}{c}\text { Observed } \\
\Sigma D^{*}\end{array}$ & $\begin{array}{c}\text { Expected } \\
\Sigma d^{*}\end{array}$ & $\Sigma \sigma^{2} d^{*}$ & $\chi^{2}$ & $p^{\dagger}$ \\
\hline \multirow[t]{3}{*}{ BL/LL leprosy } & Healthy & 28 & 22 & 20 & & n.s. \\
\hline & LL leprosy & 21 & $12 \cdot 5$ & $10 \cdot 25$ & $6 \cdot 24$ & 0.006 \\
\hline & & 49 & $34 \cdot 5$ & $30 \cdot 25$ & $6 \cdot 48$ & 0.005 \\
\hline \multirow[t]{3}{*}{ TT leprosy } & Healthy & 10 & 7 & $5 \cdot 5$ & & n.s. \\
\hline & LL leprosy & 13 & $8 \cdot 5$ & $6 \cdot 25$ & $3 \cdot 24$ & 0.04 \\
\hline & & 23 & $15 \cdot 5$ & $11 \cdot 75$ & $4 \cdot 17$ & 0.02 \\
\hline
\end{tabular}

${ }^{*} D=$ Observed difference between the number of affected siblings with one and those with the other haplotype.

$d=$ Expected difference for random segregation.

$\Sigma D>\Sigma d=$ An excess of identical HLA-haplotypes.

$\sigma^{2} d=$ Variance of $d$. For method of analysis see ref. 45 .

$\dagger p$-value is divided by 2 (one-sided significance test).

n.s. not significant.

leprosy was obtained. The combined HLA-segregation data from more than 120 families collected so far ${ }^{45,47,49,56,58}$ are presented in Table 2 .

In view of the increasing evidence of suppressor $\mathrm{T}$-cells in lepromatous leprosy ${ }^{59,18}$ the HLA-linked control of lepromatous leprosy is likely to be due to an Is gene. The existence of such, presumably, leprosy-specific immune suppression (Is) genes should have far-reaching practical and theoretical

Table 2. Children suffering from TT or BL/LL leprosy share HLA-haplotypes more frequently than expected*

\begin{tabular}{lcccc}
\hline & Observed & Expected & & \\
\multicolumn{1}{c}{ Children } & $\Sigma D$ & $\Sigma d$ & $\chi^{2}$ & $p$-value $\dagger$ \\
\hline 1. TT leprosy $\ddagger$ & 188 & $139 \cdot 6$ & $19 \cdot 36$ & $5 \times 10^{-6}$ \\
2. BL/LL leprosy & 89 & 64.5 & $10 \cdot 06$ & 0.0008 \\
3. Healthy§ & 128 & $125 \cdot 8$ & $0 \cdot 03$ & n.s. \\
\hline
\end{tabular}

* For method of analysis see ref. 45.

$\dagger p$-value divided by 2 (one-sided significance test).

$\ddagger$ Offspring of TT parents not included.

$\S$ Healthy sibs older than youngest patient only.

n.s. not significant. 
implications for prevention or therapy of the disease and for our understanding of the immune defect in lepromatous leprosy. Besides this, it could indicate that the action of Is genes is an essential aspect of the mechanisms controlling the immune response in man.

\section{Susceptibility to leprosy per se not controlled by HLA-linked genes}

As already shown in Table 2 for the combined family data, the segregation of HLA-haplotypes among healthy siblings in multi-case leprosy families was observed to occur randomly in the studies carried out so far. This repeatedly made observation argues against the existence of HLA-linked genes conferring susceptibility to leprosy per se. In the presence of such genes, a preferential segregation of parental haplotypes lacking these susceptibility genes would have been observed among the healthy sibs. Furthermore, if genes conferring susceptibility to leprosy per se were linked to HLA, one would expect those HLA haplotypes shared between all leprosy patients in a given sibship ('leprosy-haplotypes') to occur less frequently among the healthy siblings of that sibship. That this was not the case is shown in Table 3 for data obtained in India, Venezuela and China.

Therefore, whereas the type of leprosy to develop in individuals who are susceptible to leprosy seems to be determined, at least partly, by HLA-linked genes, the susceptibility to leprosy per se seems not. Most probably, the susceptibility to leprosy per se is influenced both by environmental factors and non-HLA encoded genetic factors. The latter supposition is mainly inferred from

Table 3. Analysis of the presence among healthy siblings of HLA-haplotypes which are shared among all leprosy patients in the sibship ('leprosy-haplotypes')

\begin{tabular}{|c|c|c|c|}
\hline \multirow[b]{2}{*}{ Healthy siblings* } & \multicolumn{2}{|c|}{ Number of 'leprosy-haplotypes' } & \multirow[b]{2}{*}{$p \dagger$} \\
\hline & obs. & exp. $\ddagger$ & \\
\hline India $^{47}$ & 40 & $40 \cdot 5$ & n.s. \\
\hline Venezuela $^{56}$ & 22 & 24 & $\mathrm{n}$. \\
\hline \multirow[t]{2}{*}{ China $^{58}$} & 19 & 16 & n.s. \\
\hline & 81 & $80 \cdot 5$ & n.s. \\
\hline
\end{tabular}

\footnotetext{
* Healthy sibs older than youngest patient only.

$\dagger$ Method of analysis described previously see ref. 58 .

$\ddagger$ Expectation on the basis of random haplotype distribution.

n.s. not significant.
} 
experimental mouse models, which showed for various intracellular microorganisms that the innate resistance towards them is controlled by a single gene not linked to the H-2 system (the murine MHC) ${ }^{60-62}$ The modifying influence of $\mathrm{H}$-2-linked genes only in the acquired phase of immunity has also been shown in a number of these experimental models. ${ }^{63-65}$ At variance with these findings and, therefore, of special interest could be the recent finding of control of bacterial multiplication by $\mathrm{H}-2$-linked genes in M. lepraemurium infection. ${ }^{66}$

\section{HLA-associated markers for leprosy}

The data collected so far with respect to HLA-associated markers for leprosy (types) are not clearcut. Nevertheless, from the data collected, one might infer that such markers do exist and are coded for mainly in the HLA-DR region. The evidence in favour of DR2, DR3 and MT1 being such markers has already been mentioned. Recent confirmative evidence for a role of DR3 and MT1 was obtained in the families from Venezuela (Table 4). Whereas MT1 was found to be inherited at preference by lepromatous leprosy affected children, DR3 was preferentially not inherited. In a limited population study of lepromatous leprosy in Venezuela, MT1 was also shown to be associated with this type of the disease. ${ }^{67}$ In spite of the seeming consistency in the data implicating a role of particular class II determinants (DR, MT) in the predisposition to leprosy types, the associations found so far are too weak to be of any practical use. In the hope of obtaining more useful markers for the predisposition to particular leprosy types, further association studies will have to be carried out in various populations on well-classified patients, both familial and sporadic. With the better recognition of the non-DR class II determinants and with the help of more recently developed tools such as monoclonal antibodies recognizing distinct epitopes on class II

Table 4. Inheritance of HLA-DR3 and -MT1 from, respectively, DR3and MT1- heterozygous parents in relation to leprosy status

\begin{tabular}{lcccrrr}
\hline $\begin{array}{l}\text { Leprosy status } \\
\text { children }\end{array}$ & $\begin{array}{c}\text { DR3 } \\
\text { inherited }\end{array}$ & $\begin{array}{c}\text { DR3 not } \\
\text { inherited }\end{array}$ & $p^{*}$ & $\begin{array}{c}\text { MT1 } \\
\text { inherited }\end{array}$ & $\begin{array}{c}\text { MT1 not } \\
\text { inherited }\end{array}$ & $p^{*}$ \\
\hline BL/LL leprosy & 2 & 9 & 0.03 & 30 & 17 & 0.04 \\
$\begin{array}{l}\text { TT leprosy } \\
\text { healthy }\end{array}$ & 9 & 4 & n.s. $\dagger$ & 6 & 6 & n.s. \\
& 12 & 10 & n.s. & 24 & 26 & n.s. \\
\hline
\end{tabular}

${ }^{*}$ Pr from binomial distribution with $p=50$.

$\dagger$ Significant difference between BL/LL and TT $(p=0 \cdot 02)$.

$\ddagger$ Only healthy children, being older than youngest affected child, are included in the analysis.

n.s. not significant. 
molecules and cDNA probes recognizing DNA fragments in the genome coding for HLA-Class II molecules and flanking sequencies, it is expected that the relevant genes or gene products will be recognized in a more reliable way.

\section{HLA-DR associated control of M. leprae specific immune response in vitro}

Since the cellular immune response, as measured by the lymphocyte transformation test (LTT) in sibs being HLA-identical with their TT leprosy affected sibs, did not differ from that in sibs being HLA-non-identical with their TT leprosy affected sibs, it was concluded that it would be impossible to study the expression of the HLA-linked genes predisposing to tuberculoid leprosy by a standard LTT. ${ }^{68}$ Therefore, a more sophisticated test-system was applied to study specifically the role of HLA-DR molecules in the interaction between antigenpresenting cells (APCs) and T-cells in M. leprae specific proliferative responses. ${ }^{69}$ For this purpose T-cells obtained from HLA-DR3 positive Surinam tuberculoid leprosy patients were studied for their proliferative responses against $M$. leprae antigens using monocytes obtained from various healthy individuals as APCs. In these experiments the HLA-DR restriction was shown for the first time, indicating a role of HLA-DR molecules in $M$. leprae specific proliferative responses, as was also indicated by the blocking effect of anti-DR antibodies in proliferative responses. ${ }^{70}$ Furthermore, it was observed that the responses directed against the $M$. leprae derived antigenic cell-wall fraction, MLW-1,71 obtained with DR3 homozygous monocytes as APCs were of a lower level than the responses obtained with DR-non3 homozygous monocytes (Figure 1). This, especially, indicated a poor capacity of DR3 to function as a restricting molecule in the immune response to leprosy-specific antigenic determinants. From the data

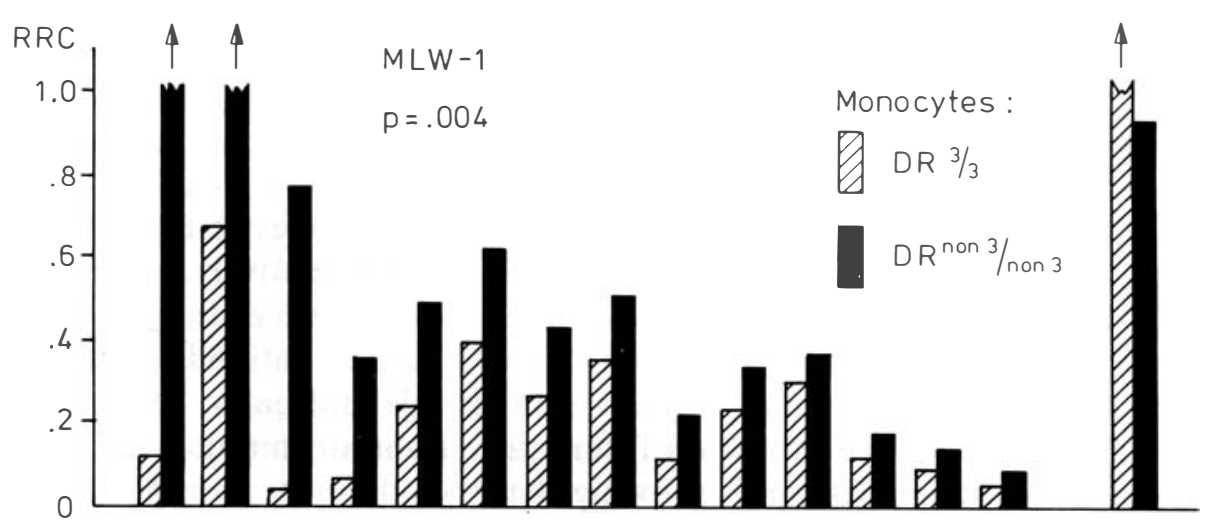

Figure 1. Proliferative responses of T-cells obtained from 15 HLA-DR3 heterozygous individual T-cell donors, co-cultured with either DR3 or DR-non3 homozygous allogeneic DR-compatible monocytes as antigen-presenting cells (APCs) for MLW-1 antigen. RRC denotes relative regression coefficient (slope) as calculated by an analysis of regression of response on MLW-1 dose. ${ }^{69}$ 
obtained it is concluded that $\mathrm{T}$-cell recognition of leprosy-specific antigens in conjunction with HLA-DR3 is poor. However, in view of the immunological features of tuberculoid leprosy, such as specific responsiveness in the standard LTT and lepromin skin-tests, one would have expected DR3-restricted responsiveness to be high rather than low. Therefore, the exact nature of the cellular mechanisms underlying the observed in vitro phenomenon should be clarified to see whether the data obtained in this experimental system are at all comparable with data obtained by the standard LTT and lepromin skin-test, and to exclude the possibility that we are measuring an in vitro artefact. Nevertheless, a poor recognition of leprosy-specific antigens could be compatible with the suggestion made in relation to skin-test data reported previously, ${ }^{72}$ namely that individuals carrying DR3 preferentially recognize mycobacterial 'common-antigens'. It is self-evident that any poor or aberrant recognition of certain leprosy-specific determinants may have crucial consequences for the specific immune response in the in vivo situation. Since the experimental data may represent an in vitro correlate for an in vivo defined HLA-association, the test-system could offer possibilities to study the differential capacity of particular HLA-DR molecules to function as restricting elements as a mechanism for the HLA-linked genetic control in leprosy.

\section{Perspectives}

The recent findings described in the present paper provide a number of starting points for further in-depth investigation. With respect to practical implications for leprosy control, but also with respect to the understanding of, presumably, some essentials of the genetic control of the immune response in man, the HLA-linked control of the susceptibility to lepromatous leprosy deserves special attention. For obvious reasons, attempts should be made to test the hypothesis of leprosy-specific Is genes. One approach could be to present leprosy antigens to $\mathrm{T}$-cells from lepromatous leprosy patients by allogeneic antigen presenting cells which share only one haplotype or one DR specificity with the T-cell. In this way, responses restricted by the responder haplotype or molecules could be obtained circumventing the involvement of Is gene products. Alternatively, attempts may be made to block the Is gene products, as was shown successfully in non-responder mice for the LDH-B antigen ${ }^{73}$ with the use of antibodies, preferably monoclonal, recognizing distinct epitopes on class II molecules. That the latter approach could have an impact on future prevention or immuno-therapy was indicated by mouse experiments showing that the administration of antibodies directed against certain class II H-2 products could prevent or modulate immunopathological disease processes. ${ }^{74,75}$ Speculating along these lines one could think of adding antibodies directed against leprosy Is gene products, possibly MT1, as non-conventional 'adjuvants' to vaccines used for prevention or 
immuno-therapy. By blocking the effect of the presumed leprosy-specific Is gene products, one might be able to convert specific non-responders into responders. A promising beneficial therapeutic effect of multiple inoculations with a mixture of M. leprae and BCG has been shown in some but not all BL and LL patients. ${ }^{76}$ The addition of the proper blocking antibodies to such a 'vaccine' could thus be one of the possibilities to raise the effectiveness of this kind of immunotherapy. To improve our understanding of the HLA-associated control in leprosy, better tools for investigation are expected to become available, namely antigen-specific T-cell lines grown from leprosy patients (and healthy controls). These can be studied for HLA-class II restriction properties for leprosy antigens presented by selected allogeneic antigen presenting cells obtained from both healthy individuals and leprosy patients.

\section{Acknowledgments}

This report is in part supported by the Dutch Foundation for Medical Research (FUNGO) which is subsidized by the Dutch Organization for the Advancement of Pure Research (ZWO), the J A Cohen Institute for Radiopathology and Radiation Protection (IRS) and the Immunology of Leprosy (IMMLEP) component of the UNDP/World Bank/WHO special Programme for Research and Training in Tropical Diseases.

\section{References}

1 De Vries RRP, Van Eden W, Van Rood JJ. HLA-linked control of the course of M. leprae infections. Lepr Rev, 1981; 52 (1)Suppl: 109-19.

2 Van Rood JJ. The HLA-system. Genetics, its role in disease susceptibility and in the immune response. In Modern Genetic Concepts and Techniques in the Study of Parasites. Michal F (ed), on behalf of the UNDP/World Bank/WHO. Basel: Schwabe \& Co, 1981, pp. 119-46.

3 Van Eden W, De Vries RRP, Van Rood JJ. The genetic approach to infectious disease with special emphasis on the MHC. Disease Markers, 1983; no. 3 (in press).

4 Thorsby E, Berle E, Nousiainen H. HLA-D region molecules restrict proliferative T-cell responses to antigen. Immunol Rev, 1982; 66: 39-56.

${ }^{5}$ Bodmer WF. Evolutionary significance of the HLA-system. Nature, 1972; 237: 139-45.

${ }^{6}$ Van Eden W, De Vries RRP, Van Rood JJ. HLA and infectious disease. In Human Genetics Part B: Medical Aspects. Bonné-Tamir (ed), New York: Alan R. Liss, 1982, pp. 37-54.

7 Morris PJ, Hors J, Royer P, Ryder LP. Other diseases. In HLA and Disease. Dausset J and Svejgaard A. (eds), Munksgaard, Copenhagen, 1977, pp. 249-55.

${ }^{8}$ Harboe M, Closs O. Immunological Aspects of Leprosy. In Immunology 80. Fougereau M and Dausset J. (eds), Academic Press, London, 1980, pp. 1231-43.

9 Ridley DS, Jopling WH. Classification of leprosy according to immunity. A five-group system. Int $J$ Lepr, 1966; 34: 255-73.

10 Godal T. Immunological aspects of leprosy-present status. Prog. Allergy, 1978; 25: 211-42.

11 Rees RJW. The significance of the lepromin reaction in man. Prog. Allergy, 1964; 8: 224-58. 
12 Godal T, Myrvang B, Frøland SS, Shao J, Melaku G. Evidence that the mechanism of immunological tolerance ('central failure') is operative in the lack of host resistance in lepromatous leprosy. Scand J Immunol, 1972; 1: 311-321.

13 Stoner GL. Ir genes and leprosy (letter). Int J Lepr, 1978; 46: 217-20.

14 Godal T, Myklestad B, Samuel DR, Myrvang B. Characterization of the cellular immune defect in lepromatous leprosy: a specific lack of circulating $M$. leprae reactive lymphocytes. Clin Exp Imm, 1971; 9: 821-31.

15 Stoner GL, Mshana RN, Touw J, Belehu A. Studies on the defect in cell-mediated immunity in lepromatous leprosy using HLA-D identical siblings: Absence of circulating suppressor cells and evidence that the defect is in the T-lymphocyte rather than the monocyte population. Scand J Immunol, 1982; 15: 33-48.

${ }^{16}$ Hirschberg H. The role of macrophages in the lymphoproliferative response to Mycobacterium leprae in vitro. Clin exp Imm, 1978; 34: 46-51.

17 Mehra V, Mason LH, Fields JP, Bloom BR. Lepromin-induced suppressor cells in patients with leprosy. J. Immunol, 1979; 123: 1813-17.

18 Haregewoin A, Godal T, Mustafa AS, Belehu A, Yemaneberhan T. T-cell conditioned media reverse T-cell unresponsiveness in lepromatous leprosy. Nature, 1983; 303: 342-4.

19 Nath I, Van Rood JJ, Mehra NK, Vaidya MC. Natural suppressor cells in human leprosy: the role of HLA-D-identical peripheral lymphocytes and macrophages in the in vitro modulation of lymphoproliferative responses. Clin Exp Imm, 1980; 42: 203-10.

20 Danielsen DC, Boeck CW. Traité de la spedalskhed ou eléphantiasis des grecs. Paris: Baillière, 1948, pp. 334-44.

${ }^{21}$ Aycock WL, McKinley EB. The roles of familial susceptibility and contagion in the epidemiology of leprosy. Int J Lep, 1938; 6: 169-84.

${ }^{22}$ Spicket SG. Genetics and the epidemiology of leprosy. Lepr Rev, 1962; 33: 76-93, 173-81.

${ }^{23}$ Beiguelman B. Lepromin reaction: Genetics studies including twin pair analysis. Acta Lepr, 1971; 44: 5-65.

${ }^{24}$ Chakravartti MR, Vogel F. A twin study on leprosy. Top Hum Genet, 1973; 1: 1-123.

25 Smith DG. The genetic hypothesis for susceptibility to lepromatous leprosy. Ann Hum Biol, 1979; 6: 375-93.

${ }^{26}$ Serjeantson S, Wilson SR, Keats BJB. The genetics of leprosy. Ann Hum Biol, 1979; 6: 375-93.

${ }^{27}$ Fine PEM. Immunogenetics of susceptibility to leprosy, tuberculosis and leishmaniasis. An epidemiological perspective. Int J Lepr, 1981; 49: 437-54.

28 Thorsby E, Godal T, Myrvang B. HL-A antigens and susceptibility to diseases. II. Leprosy. Tissue Antigens, 1973; 3: 373-7.

29 Escobar-Gutierrez A, Gorodezky C, Salazar-Mallén M. Distribution of some of the HLA-system lymphocyte antigens in Mexicans. Vox Sang. 1973; 25: 151-5.

${ }^{30}$ Kreisler M, Arnaiz A, Perez B, Fernandez Cruz E, Bootello A. HLA-A antigens in leprosy. Tissue Antigens, 1974; 4: 197-201.

${ }^{31}$ Reis AP, Maia F, Reis V, Andrade IM, Campus AAS. HL-A antigens i n leprosy. Lancet, 1974; ii: 1384.

${ }^{32}$ Smith GS, Walford R, Shepard CC, Payne R, Prochazka GJ. Histocompatibility antigens in leprosy. Vox Sang, 1975; 28: 42-9.

33 Dasgupta A, Mehra NK, Ghei SK, Vaidya MC. Histocompatibility antigens (HLA-A) in leprosy. Tissue Antigens, 1975; 5: 85-7.

${ }^{34}$ Rea TH, Levan NE, Terasaki P. Histocompatibility antigens in patients with leprosy. $J$ Infect Dis, 1976; 134: 615-18.

35 Mehra NK, Dasgupta A, Ghei SK, Nilikanta Rao MS, Vaidya MC. HLA antigens and leprosy. Microbios. Letters, 1976; 3: 79-83.

${ }^{36}$ Nakajima S, Kobayashi S, Nohara M, Sato S. HLA antigens and susceptibility to leprosy. Int J Lepr, 1977; 45: 273-7. 
37 Youngchaiyud U, Chandanayingyong D, Vibahatavanija T. The incidence of HLA antigens in leprosy. Vox Sang, 1977; 32: 342-4.

38 Takata H, Sada M, Ozawa S, Sekiguchi S. HLA and mycobacterial infection: increased frequency of B8 in Japanese leprosy. Tissue Antigens, 1978; 11: 61-4.

${ }^{39}$ Greiner J, Schleiermacher E, Smith T, Lenhard V, Vogel F. The HLA-system and leprosy in Thailand. Hum Genet, 1978; 42: 201-13.

${ }^{40}$ Massoud A, Nikbin B, Nazari GR, Syadat NA, Ala F. A study of cell mediated immunity and histocompatibility antigens in leprosy patients in Iran. Int J Lepr, 1978; 46: 149-53.

${ }^{41}$ Chiewsilp P, Ashkambhira S, Chirachariyavej T, Bhamavapravati N, Entwistle C. The HLA antigens and leprosy in Thailand. Tissue Antigens 1979; 13: 186-8.

42 Chan SH, Oon BB, Kamarudin A, Wee GB. HLA and leprosy in Chinese. Tissue Antigens, 1979; 13: 73-4.

${ }^{43}$ Mohagheghpour N, Tabatabai H, Mohammad K, Ramahujam K, Modabber FZ. Histocompatibility antigens in patients with leprosy from Azerbaijam, Iran. Int J Lepr, 1979; 47: 597-600.

${ }^{44}$ McDevitt HO, Bodmer WF. HLA, immune response genes and disease. Lancet, 1974; 1: 1269-75.

45 De Vries RRP, Lat A Fat RFM, Nijenhuis LE, Van Rood JJ. HLA-linked genetic control of host response to Mycobacterium leprae. Lancet, 1976; 1: 1328-30.

46 De Vries RRP, Mehra NK, Vaidya MC, Gupte MD, Meera Khan P, Van Rood JJ. HLA-linked control of susceptibility to tuberculoid leprosy and association with HLA-DR types. Tissue Antigens, 1980; 16: 294-304.

${ }^{47}$ Fine PEM, Wolf E, Pritchard J, Watson B, Bradley DJ, Festenstein H, Chacko CJG. HLA-linked genes and leprosy: a family study in a South Indian population. J Infect Dis, 1979; 140: 152-61.

${ }^{48}$ Serjeantson SW. HLA and susceptibility to leprosy. Imm Rev, 1982; 70: 24-47.

49 Van Eden W, De Vries RRP, Mehra NK, Vaidya MC, D’Amaro J, Van Rood JJ. HLA segregation of tuberculoid leprosy: Confirmation of the DR2 marker. J Infect Dis, 1980; 141: 693-701.

50 Van Eden W, Mehra NK, Vaidya MC, D'Amaro J, Schreuder GMTh, Van Rood JJ. HLA and sporadic tuberculoid leprosy: A population study in Maharashtra, India. Tissue Antigens, 1981; 18: 189-93.

51 Rea TH, Terasaki PI. HLA-DR antigens in tuberculoid and lepromatous leprosy. Lepr Rev, 1980; 51: 117-23.

52 Izumi S, Sugiyama K, Matsumoto Y, Ohkawa S. Analysis of the immunogenetic background of Japanese leprosy patients by the HLA-system. Vox Sang, 1982; 42: 243-47.

53 Serjeantson SW, Vaidya MC, Chan SH, Juji GT, Mehra NK, Naik S, Sasazuki T. Leprosy: joint results of the 2nd AOHWC study. In Proceedings of the Second Asia-Oceania Workshop and Conference, Simons $\mathrm{M}$ and Tait $\mathrm{B}$ (eds) (in press).

54 Miyanaga K, Juji T, Maeda H, Nakajima S, Kobayashi S. Tuberculoid leprosy and HLA in Japanese. Tissue Antigens, 1981; 18: 331-4.

55 Van Eden W, De Vries RRP, D'Amaro J, Schreuder GMTh, Leiker DL, Van Rood JJ. HLA-DR associated genetic control of the type of leprosy in a population from Surinam. Human Immunol, 1982; 4: 343-50.

56 Van Eden W, Gonzalez NM, De Vries RRP, Convit J, Van Rood JJ. HLA-segregation in multi-case leprosy families indicating HLA-linked control of predisposition to lepromatous leprosy. Submitted for publication.

${ }^{57}$ Harboe M, Genetic aspects of leprosy. In Modern Genetic Concepts and Techniques in the Study of Parasites, Michal F. (ed.), on behalf of the UNDP/World Bank/WHO. Basel: Schwabe \& Co. 1981, pp. 387-409.

58 Xu Keju, De Vries RRP, Fai Hongming, Van Leeuwen, A, Chen Renbiao, Ye Ganyun. HLA-linked control of predisposition to lepromatous leprosy. Submitted for publication. 
59 Mehra V, Convit J, Rubinstein A, Bloom BR. Activated suppressor T-cells in leprosy. $J$ Immunol, 1982; 129: 1946-51.

60 Plant JE, Blackwell JH, O'Brian AD, Bradley DJ, Glynn AA. Are the Lsh and Ity disease resistance genes at one locus on mouse chromosome 1? Nature, 1982; 297: 510-11.

${ }^{61}$ Skamene E, Gros P, Forget A, Kongshavn AL, St. Charles C, Taylor BA. Genetic regulation of resistance to intracellular pathogenesis. Nature, 1982; 297: 506-9.

62 Brown IN, Glynn AA, Plant J. Inbred mouse strain resistance to Mycobacterium lepraemurium follows the Ity/Lsh pattern. Immunology, 1982; 47: 149-56.

${ }^{63}$ Blackwell J, Freeman J, Bradley D. Influence of $\mathrm{H}-2$ complex on acquired resistance to Leishmania donovani infection in mice. Nature, 1980; 283: 72-4.

${ }^{64}$ Skamene E, Kongshavn, PAL, Sachs DH. Resistance to Listeria monocytogenes in mice: genetic control by genes that are not linked to the H-2 complex. J Infect Dis, 1979; 139: 228-31.

${ }^{65}$ Curtis J, Adu HO, Turk JL. H-2 linkage control of resistance to subcutaneous infection with Mycobacterium lepraemurium.

${ }^{66}$ Closs O, Løvik M, Wigzell H, Taylor BA. H-2 linked gene(s) influence the granulomatous reaction to viable Mycobacterium lepraemurium in the mouse. Scand J Immunol, 1983; 18: $59-63$.

${ }^{67}$ Ottenhoff THM, Gonzalez NM, De Vries RRP, Convit J, Van Rood JJ. Association of HLA-LB-E12 (MB1, MT1) with lepromatous leprosy in a Venezuelan population. Tissue Antigens, 1984, in press.

68 Van Eden W, Elferink BG, De Vries RRP. An approach to study in vitro the expression of HLA-encoded genetic factors predisposing to tuberculoid leprosy. J. Immunogenet, 1983; 10: $107-14$.

69 Van Eden W, Elferink BG, De Vries RRP, Leiker DL, Van Rood JJ. Low T-lymphocyte responsiveness to Mycobacterium leprae antigens in association with HLA-DR3. Clin Exp Immunol, 1984; 55: 140-148.

${ }^{70}$ Haregewoin A, Yemaneberhan T, Belehu A. The role of products of the human HLA-DR locus (Ia molecules) in in vitro M. Le prae driven lymphoproliferation. Clin Exp Immunol, 1983; 53: 328-34.

71 Closs O, Reitan LJ, Negassi K, Harboe M, Belehu A. In vitro stimulation of lymphocytes in leprosy patients, healthy contacts of leprosy patients, and subjects not exposed to leprosy. Comparison of an antigen fraction prepared from Mycobacterium leprae and tuberculin purified protein derivative. Scand J Immunol, 1982; 16: 103-15.

72 Van Eden W, De Vries RRP, Stanford JL, Rook GAW. HLA-DR3 associated genetic control of response to multiple skin tests with new tuberculins. Clin Exp Imm, 1983; 52: 287-92.

${ }^{73}$ Nagy ZA, Baxevanis CN, Ishii N, Klein J. Ia antigens as restriction molecules in Ir-gene controlled T-cell proliferation. Immunol. Rev, 1981; 60: 59-83.

74 Green WF, Colley DG. Modulation of Schistosoma mansoni egg-induced granuloma formation: I-J restriction of T-cell mediated suppression in a chronic parasitic infection. Proc Natl Acad Sci USA, 1981; 78: 1152-6.

75 Steinman L, Rosenbaum JT, Sriram S, McDevitt HO. In vitro effects of antibodies to immune response gene products: Prevention of experimental allergic encephalitis. Proc Natl Acad Sci USA, 1981; 7: 7111-14.

76 Convit J, Aranzazu N, Ulrich M, Pinardi, ME, Reyes O, Alvarado J. Immunotherapy with a mixture of Mycobacterium leprae and BCG in different forms of leprosy and in Mitsuda-negative contacts. Int J Lepr, 1982; 50: 415-24. 